\title{
Prevalence and severity of periodontal diseases among Nepalese adults - a hospital based study
}

\section{Rajkarnikar J1 , Acharya $\mathrm{J}^{2}$}

${ }^{1}$ Department of Periodontics and Implantology, ${ }^{2}$ Department of Community Dentistry, College of Dental Sciences and Hospital- Nepal Medical College (CODSH- NMC), Attarkhel, Nepal

\section{ABSTRACT}

\section{Objective}

The present study was undertaken to determine the prevalence of periodontal diseases among adults visiting the dental department of a hospital based in Jorpati.

\section{Methods}

Four hundred and seventeen patients were randomly taken from a dental hospital situated in Jorpati during the time period of March 2013 to August 2013. All patients visiting the dental department who fulfilled the inclusion criteria were included in the study. The data included patients overall information along with their chief complaint, gingival bleeding on probing (BOP), probing depth (PD), frequency of brushing, adverse habits and the diagnosis of the patients examined.

\section{Results}

We found that $52.5 \%$ suffered from gingivitis and $47.5 \%$ suffered from periodontitis. Also $28.3 \%$ suffered from localized and $18 \%$ suffered from generalized form of periodontitis. There was no statistically significant difference in the gender when the prevalence of periodontal disease was compared. 51.4\% of male and $44.4 \%$ of female was seen to be affected with periodontitis. Also habits like smoking and intake of smokeless tobacco was seen to be associated with periodontitis. Regarding the age group more number of patients in the age group of $>50$ years were seen to be suffering from periodontitis (84.3\%) as compared to age group of $\leq 35$ years $(25.9 \%)$.

\section{Conclusion}

There is high prevalence of periodontitis and gingivitis in the studied population. Periodontitis was seen to be more prevalent as age advanced which can be attributed mainly to untreated gingivitis. However, no significant difference was seen in the prevalence of periodontitis with respect to gender.

Key words: Gingivitis, Nepal, periodontitis, prevalence

Correspondence: Dr. Junima Rajkarnikar.

E-mail: drjunima@gmail.com 
Journal of College of Medical Sciences-Nepal, 2014, Vol-10, No-1

\section{INTRODUCTION}

Epidemiology is the study of the distribution and determinants of health- related states or events in specified populations and the application of this study to control health problems. Basically the purpose of epidemiology is to apply the knowledge gained from studies to "promote, protect and restore health". ${ }^{1}$

Gingivitis is a non-destructive periodontal disease. Periodontitis is a group of inflammatory diseases affecting the supporting tissues of the tooth. ${ }^{1}$ The American Academy of Periodontology (AAP) has classified periodontitis into aggressive periodontitis $(\mathrm{AgP})$, chronic periodontitis $(\mathrm{CP})$ and periodontitis as a manifestation of systemic diseases. ${ }^{2}$ Both $\mathrm{AgP}$ and $\mathrm{CP}$ have a multifactorial etiology with dental plaque as the initiating factor. ${ }^{3}$

The prevalence of periodontal diseases varies in different regions of the world and there are indications that they may be more prevalent in developing than in developed countries ${ }^{4,5}$

Epidemiological studies that have been performed in many parts of the world indicate that periodontal diseases of varying severity are of nearly universal in adolescents. The prevalence of gingivitis is virtually $100 \%$ in a population with no oral hygiene and declines with improved oral hygiene. ${ }^{6}$ The prevalence of periodontitis has been reported by the World Health Organization (WHO) which showed a prevalence of severe periodontitis in around $8-10 \%$ of the Population. $^{7}$

Periodontal diseases have potential effects on a wide range of systemic conditions like coronary heart disease (CHD), atherosclerosis, myocardial /cerebral infarction, stoke, diabetes mellitus, preterm/low birthweight (LBW) baby, chronic obstructive pulmonary disease, acute respiratory infections and so on. ${ }^{8}$

A very limited number of epidemiological studies have been carried out to determine the prevalence of oral diseases in Nepal. We have done our study in Jorpati which is a very large village in Kathmandu District in the Bagmati Zone of central Nepal.

\section{MATERIALS AND METHODS}

This is a hospital based study where all patients visiting the department of Oral Medicine and Radiology, in a dental hospital situated in Jorpati were taken during the time period of March 2013 to August 2013. Informed consents was obtained from the participants prior to the commencement of the study. Total number of patients examined was 417 . For each participant, full mouth periodontal examination was performed and recorded on a special examination form. The clinical examinations were carried out using a sterilized Williams's periodontal probe and mouth mirror, under artificial illumination of dental chair. Face mask and examination gloves were worn by the examiner to prevent cross-infection.

The examination form included patients' general information along with their purpose of dental visit, gingival bleeding on probing (BOP), probing depth (PD), frequency of brushing, adverse habits and the diagnosis of the patients examined. Full mouth pocket depth was probed for the diagnosis of periodontal disease. Statistical analysis was performed using SPSS version 17.0 and test for association was performed using Pearson's Chi- square test.

\section{RESULTS}

Among the patients examined, $44.6 \%$ were male whereas $55.4 \%$ were female. The frequency of the age group was $52.8 \%$ in the age group of $\leq 35$ years, $25.9 \%$ in the age group of $35-50$ years and $21.3 \%$ in the age group of $>50$ years. Out of the total patients examined, $47.5 \%$ suffered from periodontitis whereas $52.5 \%$ suffered from gingivitis. On asking for the 
Rajkarnikar et al. Prevalence and severity of periodontal..........

purpose of their visit to the Dental hospital, $15.6 \%$ came for routine dental visit, $35.5 \%$ came due to some kind of pain, $11.8 \%$ had complains of stains or deposits in teeth, $28.1 \%$ came with periodontal related problems like bleeding/swollen gums whereas 9.1\% had other reasons (Fig. 1). In our study $68.8 \%$ brushed once daily whereas $29.5 \%$ brushed twice daily whereas $1.7 \%$ brushed occasionally (Fig. 2). Out of these, $28.3 \%$ suffered from localized periodontitis, $18.0 \%$ from generalized gingivitis and $0.2 \%$ from Aggressive periodontitis, $13.4 \%$ also had gingival enlargement due to some underlying systemic conditions (Fig. 3). Among the adverse habits, $13.9 \%$ were smokers, $6 \%$ consumed smokeless tobacco and 5.3\% consumed both (Fig. 4). Although not statistically significant, both males and females equally suffered from various types of periodontal disease (Table 1).

The prevalence of gingivitis was higher among patients of age group of $\leq 30$ years $(74.1 \%)$ as compared to that of other age groups. However, in the age group of more than 50 years, more people (84.3\%) suffered from periodontitis (Table 1). Among the age group of $\leq 35$ years, $21.4 \%$ suffered from localized form whereas $3.2 \%$ suffered from generalized form of periodontitis as compared to $37.1 \%$ of $>50$ years old group who suffered from localized form and $47.2 \%$ who suffered from generalized form of periodontitis. $(p<0.005)$ (Table 2). All of patients who used smokeless tobacco and $84.5 \%$ of the smokers suffered from various forms of periodontitis (Table 1).

Table 1 Prevalence of Gingivitis and Periodontitis with various factors

\begin{tabular}{|c|c|c|c|}
\hline Age & Gingivitis (\%) & Periodontitis (\%) & P value \\
\hline$\leq 35$ & $163(74.1 \%)$ & $57(25.9 \%)$ & \\
\hline $35-50$ & $42(38.9 \%)$ & $66(61.1 \%)$ & 0.000 \\
\hline$>50$ & $14(15.7 \%)$ & $75(84.3 \%)$ & \\
\hline \multicolumn{4}{|l|}{ Gender } \\
\hline Male & $90(48.6 \%)$ & $95(51.4 \%)$ & 0.158 \\
\hline Female & $129(55.6 \%)$ & $103(44.4 \%)$ & \\
\hline \multicolumn{4}{|l|}{ Brushing habits } \\
\hline Once & $139(48.4 \%)$ & $148(51.6 \%)$ & \\
\hline Twice & $80(65 \%)$ & $43(35 \%)$ & 0.000 \\
\hline occasional & $0(0 \%)$ & $7(100 \%)$ & \\
\hline \multicolumn{4}{|l|}{ Adverse habits } \\
\hline None & $207(66.3 \%)$ & $105(33.7 \%)$ & \\
\hline Smoker & $9(15.5 \%)$ & $49(84.5 \%)$ & 0.000 \\
\hline Smokeless tobacco & $0(0 \%)$ & $25(100 \%)$ & \\
\hline Both & $3(13.6 \%)$ & $19(86.4 \%)$ & \\
\hline \multicolumn{4}{|l|}{ Medical history } \\
\hline None & $207(62.2 \%)$ & $126(37.8 \%)$ & \\
\hline Diabetes & $0(0 \%)$ & $13(100 \%)$ & \\
\hline Hypertension & $2(6.1 \%)$ & $31(93.9 \%)$ & 0.000 \\
\hline Both & $0(0 \%)$ & $21(100 \%)$ & \\
\hline Others & $10(58.8 \%)$ & $7(41.2 \%)$ & \\
\hline
\end{tabular}


Journal of College of Medical Sciences-Nepal, 2014, Vol-10, No-1

Table 2 Prevalence of various forms of periodontal disease with age

$\begin{array}{ccccccc}\text { Age } & \text { Chronic } & \text { Localised } & \text { Generalized } \\ \text { (years) } & \text { gingivitis } & \text { periodontitis } & \text { Aggressive } & \text { Gingival } & P \\ \text { periodontitis } & \text { periodontitis } & \text { enlargement } & \text { value } \\ 355 & 121(55 \%) & 47(21.4 \%) & 7(3.2 \%) & 1(0.5 \%) & 44(20 \%) & \\ >50 & 38(35.2 \%) & 38(35.2 \%) & 26(24.1 \%) & 0(0 \%) & 6(5.6 \%) & 0.000 \\ & 8(9 \%) & 33(37.1 \%) & 42(47.2 \%) & 0(0 \%) & 6(6.7 \%) & \end{array}$

Fig. 1: Frequency for purpose of dental visit

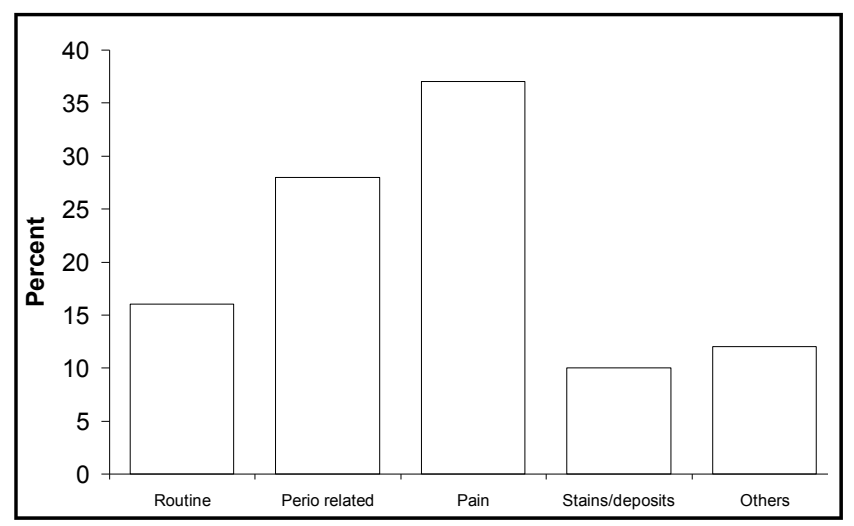

Fig. 2: Frequency of brushing habits

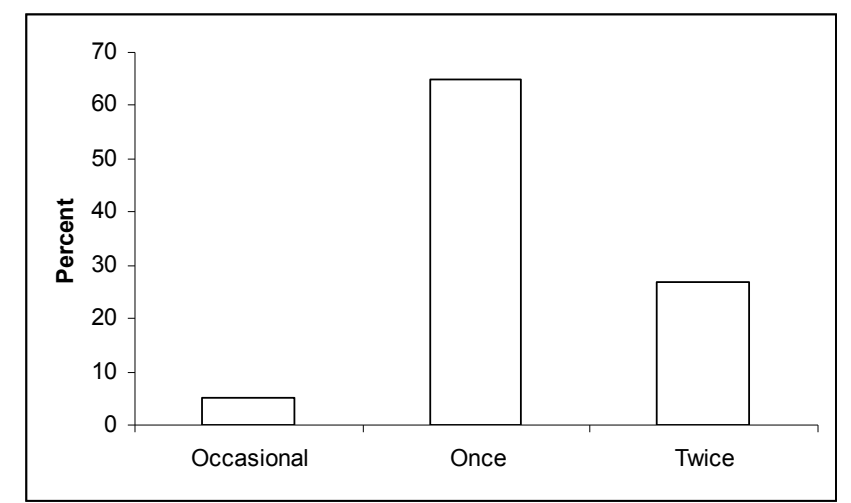

Fig. 3: Frequency of various forms of periodontal

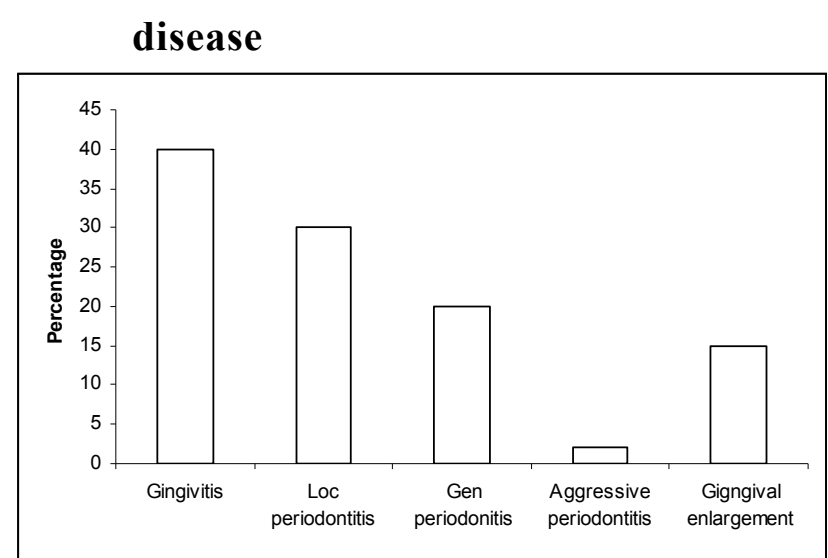

Fig. 4: Frequency of adverse habits

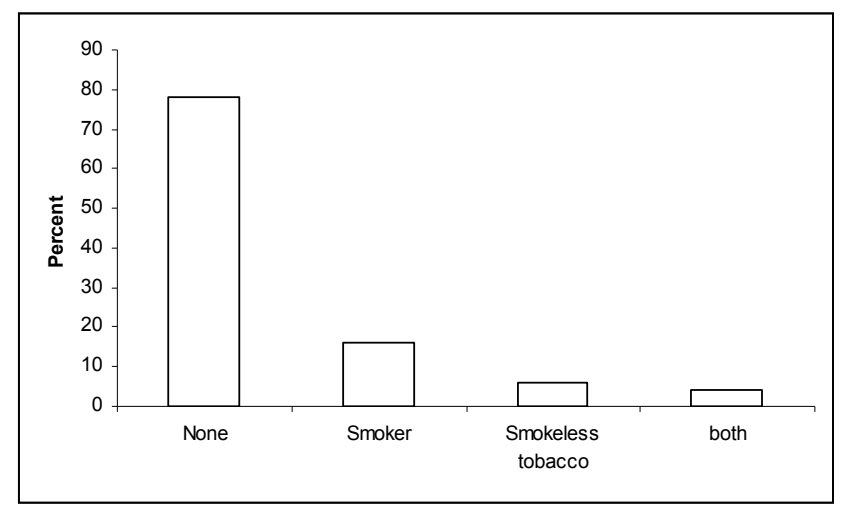

\section{DISCUSSIONS}

In our study, the prevalence of periodontitis was $47.5 \%$ and of gingivitis was $52.5 \%$ among which $28.3 \%$ suffered from localized form and $18 \%$ suffered from generalized form of periodontitis. The remaining $0.2 \%$ had aggressive periodontitis and $13.4 \%$ had gingival enlargements (Fig, 2). Naseem Shah ${ }^{9}$ in his report for the National Commission on Macroeconomics observed more advanced periodontal disease affecting $40-45 \%$ of the population of India. Arvidson-Bufano ${ }^{10}$ found shallow pockets in $34 \%$ of the urban slum group and in $42 \%$ of the rural group, in a survey done in Central and Western Bangladesh. GPI Singh ${ }^{11}$ in his prevalence study done in Ludhiana and found that the urban subjects had more prevalence of moderate and severe periodontitis than rural subjects. Md. Zahid Hossain et $1 .{ }^{12}$ had done a year long study in which 
Rajkarnikar et al. Prevalence and severity of periodontal..........

gingivitis cases were found to be $63.2 \%$ and periodontitis was $36.8 \%$ which was concurrent with the findings of our study where the prevalence of peiodontitis was $47.5 \%$. Ababneh ${ }^{13}$ et al. concluded in his study that $76 \%$ had gingivitis, $2.2 \%$ had AgP and $5.5 \%$ had CP. In his study the prevalence of periodontitis increased with age, which was similar to what was observed in our study. His study also showed periodontitis to be more frequent among males as compard to females. In our study, although not statistically significant, more females suffered from gingivitis (55.6\%) as compared to males (48.6\%).As shown in table $1,51.4 \%$ of males suffered from periodontitis as compared with $44.4 \%$ of females. $(\mathrm{p}>0.005)$.

Among the age group of $\leq 35$ years, $21.4 \%$ suffered from localized form whereas $3.2 \%$ suffered from generalized form of periodontitis as compared to $37.1 \%$ of $>50$ years old group who suffered from localized form and $47.2 \%$ who suffered from generalized form of periodontitis. $(p<0.005)$ David $\mathrm{J}^{14}$ et al in 2011 in his study done among adults in Nepal showed periodontal pocket 4 to $5 \mathrm{~mm}$ was predominantly seen among illiterates and those with primary or unfinished secondary school education(PSE) and those who used non-fluoridated dentifrice. Periodontal pocket of $6 \mathrm{~mm}$ was observed among illiterates and those with PSE and those who used non-fluoridated dentifrice. His study also showed that chewing betel nut had a protective effect with regard to calculus formation.

Regarding the adverse habits in our study, all of patients who used smokeless tobacco and $84.5 \%$ of those who smoked suffered from various forms of periodontitis. Habits like smoking and tobacco chewing was shown to be a significant risk factor for periodontal diseases. ${ }^{14,15}$ Smoking may alter neutrophil chemotaxis, phagocytosis and oxidative burst. It can also increase secretion of tumor necrosis factor alpha, prostaglandin $\mathrm{E} 2$, neutrophil collagenase and elastase in gingival crevicular fluid. ${ }^{1,16}$

Regarding the purpose of the visit to the dental hospital majority of them $(35.5 \%)$ visited due to some kind of pain, whereas only $15.6 \%$ came for routine dental check up (Fig. 1). Similar results were seen in a study done by Humagain $M^{17}$ in which he showed that only $20 \%$ were regular dental attendees. Also he reported that only $35.1 \%$ of the study sample brushes their teeth at least twice daily while $64.9 \%$ reported regular brushing once daily which was similar to our study which showed that $68.8 \%$ brushed once daily whereas $29.5 \%$ brushed twice daily (Fig 3).

\section{CONCLUSION}

Untreated periodontitis results in tooth loss in many cases. Also it has been proved that there is a risk of preterm low birth weight babies, coronary artery diseases, diabetes, rheumatoid arthritis, etc. associated with the inflammatory mediators of periodontitis hence greater effort should be made in providing periodontal health and educating about it to the people of Nepal. ${ }^{8}$

\section{REFERENCES}

1. Newman HG, Takei H, Klokkevold PR, et al. Carranza's Clinical Periodontology. $10^{\text {th }}$ edi. Saunders Elsevier, 2009.

2. Armitage GC. Development of a classification system for periodontal disease and conditions. Ann Periodontol 1999;4:1-6. 
3. Page RC, Offenbacher S, Schroeder HE, et al. Advances in the pathogenesis of periodontitis: summary of developments, clinical implications and future directions. Periodontol 2000 1997;14:216-48.

4. Baelum V, Fejerskov O, Karring T. Oral hygiene, gingivitis and periodontal breakdown in adult Tanzanians. J Periodontal Res 1986;21:221-32.

5. Stoltenberg JL, Osborn JB, Pihlström BL, et al. Prevalence of periodontal disease in a health maintenance organization and comparisons to the national survey of oral health. J Periodontol 1993;64:853-8.

6. Bergenholtz A, Jorkjend L. Some modern aspects of periodontal disease. The Saudi Dent J 1990;2(4):156-64.

7. Merchant AT, Oranbandid S, Jethwani M, et al. Epidemiology of Periodontal Diseases. J Periodontol 2005;76:1406-19.

8. Rajkarnikar J, Thomas BS, Rao SK. InterRelationship Between Rheumatoid Arthritis and Periodontitis. Kathmandu Univ Med J 2013;41(1):22-6.

9. Shah N. Oral and dental diseases: National Commission on Macroeconomics and Health, Ministry of Health \& Family Welfare, Government of India, New Delhi Sept 2005, 27598.

10. Arvidson-Bufano UB, Holm AK. Dental health in urban and rural areas of central and western Bangladesh. Odontostomatol Trop 1990;13(3):816.
11. Singh GPI, Bindra J, Soni. Prevalence of Periodontal diseases in urban and rural areas of Ludhiana, Punjab. Indian Journal of Community Medicine 2005;30(4):128-9

12. Hossain M Z, Fageeh HN, Elagib MFA, et al . Prevalence of Periodontal Diseases among Patients Attending the Outpatient Department at the College of Dentistry, King Khalid University, Abha, Saudi Arabia. City Dent Coll J 2013;10:912.

13. Ababneh KT, Abu Hwaij ZMF, Khader YS. Prevalence and risk indicators of gingivitis and periodontitis in a Multi-Centre study in North Jordan: a cross sectional study. BMC Oral Health 2012;12(1):1-8

14. David J, Yee R, Lama D. The Periodontal Health of Adult Nepalese. Oral Health \& Preventive Dentistry 2011;9(1):67-81.

15. Parmar G, Sangwan P, Vashi P, et al. Effect of chewing a mixture of areca nut and tobacco on periodontal tissues and oral hygiene status. J Oral Sci 2009;50(1):57-62.

16. Sumanth S, Bhat KM, Bhat GS. Periodontal health status in pan chewers with or without the use of tobacco. Oral Health Prev Dent 2008;6(3):223-9.

17. Humagain M. Evaluation of knowledge, attitude and practice (KAP) about oral health among secondary level students of rural Nepal - A questionnaire study. WebmedCentral Dentistry 2011;2(3):WMC001805 